\title{
Purification of Endoxylanase from Bacillus pumilus B20 for Production of Prebiotic Xylooligosaccharide Syrup; An In vitro Study
}

\author{
Karuppasamy Geetha ${ }^{1,2}$ and Paramasamy Gunasekaran ${ }^{1,3^{*}}$ \\ ${ }^{1}$ Department of Genetics, Centre for Excellence in Genomic Sciences, School of Biological Sciences, Madurai Kamaraj \\ University, Madurai, Tamil Nadu, India. \\ ${ }^{2}$ Department of Biotechnology, Center for Research, Kamaraj College of Engineering and Technology, Virudhunagar, Tamil \\ Nadu, India. \\ ${ }^{3}$ Pro Vice Chancellor, VIT University, Chennai Campus, Vandalur-Kelamabakkam Road, Chennai, India \\ "Corresponding author: Paramasamy Gunasekaran, Pro Vice Chancellor, VIT University, Chennai Campus, Vandalur-Kelamabakkam Road, Chennai - 600 \\ 127, India. Tel: +91 452 2458478, Fax: +91 452 2459873, E-mail: gunagenomics@gmail.com and geethabt@kamarajengg.edu.in
}

Received: 28 February 2016; Revised: 20 August 2017； Accepted: 5 September 2017;

Published online: 29 December 2017

Background: The need for more cost-effective compounds is imperative because the demand for prebiotic compounds is
ever on the rise.
Objective: The focus of this study is the purification of the endoxylanase from Bacillus pumilus $\mathrm{B} 20$ and its application in a
cost-effective production of the prebiotic xylooligosaccharide (XOS) syrup having a high concentration of oligosaccharides.
Materials and Methods: The extracellular endoxylanase was purified using ammonium sulphate fractionation, DEAE
anion exchange, and Sephacryl gel filtration chromatography. The enzymatically produced XOS was used in the preparation
of XOS syrup adopting the method of ultrafiltration with 10 and $3 \mathrm{kDa}$ molecular weight cut-off (MWCO) membranes.
Culture-dependent technique for the bacterial enumeration using selective probiotic microorganisms in an in vitro analysis
was employed to confirm the prebiotic nature of XOS syrup.
Results: The molecular mass of the purified xylanase (XylB) was found to be approximately $85 \mathrm{kDa}$ with the optimum pH
and temperature of 6.5 and $60^{\circ} \mathrm{C}$, respectively. XylB hydrolyzed the xylan and produced short-chain xylooligosaccharides
(XOS). At the end of the two-step ultrafiltration process, the hydrolysate was refined to form XOS syrup (44.4\%) consisting
of XOS with a degree of polymerization (DP) between 2 and 5 , and $>5$. Among all the tested probiotic strains, Lactobacillus
brevis exhibited maximum growth in the presence of $0.5 \%$ XOS syrup with a specific growth rate of 1.2 h ${ }^{-1}$.
Conclusion: Through this study, we have identified a method to produce XOS syrup that can be used as an effective
prebiotic supplement for the growth of several probiotic strains. Human gut probiotics was used as a model system for in
vitro analysis of prebiotic oligosaccharide XOS, but for further confirmation of the prebiotic activity, in vivo feeding studies
using animal models are needed to be carried out.
Keywords: Bacillus pumilus, Endoxylanase, Probiotic, XOS syrup, Wheat bran.

\section{Background}

Hemicellulose, found in the cell walls of monocots and hard woods, comprises mainly of $\beta-1,4$-xylan (1). Xylan is a heteroglycan with a backbone of $\beta-(1-4)$ linked D-xylopyranose residues substituted at the 2' and 3' positions with L-arabinofuranose, D-glucuronic acid and 4-O-methyl-D-glucuronic acid. The complete hydrolysis of xylan involves the collective action of endoxylanase (EC 3.2.1.8), exoxylanase ( $\beta$-Dxylan xylohydrolase, EC 3.2.1.72), $\beta$-D-xylosidase (EC 3.2.1.37) and so on (2). But the hydrolysis of xylan by endo-1,4- $\beta$-xylanase results in short-chain xylooligosaccharides (XOS) of variable lengths (3). Xylanase is synthesized by many microorganisms such as Aspergillus giganteus, Aspergillus niger, Chaetomium trilateral, Bacillus subtilis, and Bacillus pumilus (4, $5,6,7,8)$. Bacillus sp. is used more extensively in the fermentation based industries than other bacteria since its enzymes are secreted extracellularly (1). The downstream processing of the extracellular xylanases is more cost-effective than intracellular enzymes. Multiple isoforms of the xylanases, secreted by Bacillus

Copyright (C) 2017 The Author(s); Published by National Institute of Genetic Engineering and Biotechnology. This is an open access article, distributed under the terms of the Creative Commons Attribution-NonCommercial 4.0 International License (http://creativecommons.org/licenses/ by-nc/4.0/) which permits others to copy and redistribute material just in noncommercial usages, provided the original work is properly cited. 
sp., enhance the hydrolysis of the lignocellulosic agricultural waste resulting in formation of valuable byproducts (9).

Xylanolytic enzyme is effectively used in various industries including treatment of pulp and paper in paper industries $(3,10)$, for increasing dough viscosity, bread volume, and shelf life in the bread and bakery industries (11), to improve body mass and digestibility of animals in the animal feed industry (12), in the bioconversion of lignocellulose into valuable byproducts and, clarification of the fruit juices. The products of xylan hydrolysis (XOS) can be used in chemical, nutritional and food industries. These prebiotics are food constituents that selectively stimulate the development and activity of beneficial bacteria like Bifidobacteria and Lactobacilli, which have immense health benefits. They enhance the microbial balance in the intestines. Prebiotics are also used in the production of substitute synthetic sweeteners (xylitol) (13).

The market today is flooded with many prebiotic preparations containing only a minor fraction of oligosaccharide (20-30\%). For example, xylooligosaccharide (Suntory, Japan) is found to contain only $29.4 \%$ oligosaccharide while $41 \%$ starch, and $15 \%$ monosaccharide. Thus, prebiotics with an increased content of oligosaccharides is the need of the present time.

\section{Objective}

The purpose of this study is the purification of endoxylanase from Bacillus pumilus B20 and its application in a cost effective production of prebiotic xylooligosaccharide (XOS) syrup having a high concentration of oligosaccharides.

\section{Materials and Methods}

\subsection{Bacterial Strain and Culture Condition}

$B$. pumilus $B 20$, isolated by the authors, from paper mill soil sample, as described previously (14), was used in this study. The strain was deposited in the Microbial Type Culture Collection and Gene Bank, Chandigarh, India and assigned with accession number [MTCC:10209]. The production medium comprised of (g.L $\left.\mathrm{L}^{-1}\right): \mathrm{K}_{2} \mathrm{HPO}_{4}, 2.0 ; \mathrm{MgSO}_{4} \cdot 7 \mathrm{H}_{2} \mathrm{O}, 0.30 ; \mathrm{CaCl}_{2} \cdot 2 \mathrm{H}_{2} \mathrm{O}$, 0.01 ; $\mathrm{NaCl}, 2$; peptone, 5.0; yeast extract, 4.0; and wheat bran, 50 (14). The initial $\mathrm{pH}$ of the medium was adjusted to 7.5 by adding $1 \%(\mathrm{w} / \mathrm{v}) \mathrm{NaOH}$.

\subsection{Assays}

The xylanase activity was determined according to Bailey et al. (15), by measuring the amount of reducing sugars released using 3, 5- dinitrosalicylic acid (DNS) method (16). One unit of the enzyme activity (U) was defined as the amount of enzyme that catalyzed the release of $1 \mathrm{~mol}$ of reducing sugars equivalent to xylose per minute under specified conditions.

Carboxymethyl cellulase(CMCase) and $\beta$-Xylosidase activities were assayed by using standard procedures according to Lynd et al. (17). Protein concentration was estimated according to Lowry et al. (18), using bovine serum albumin (Sigma, St. Louis, USA) as a standard.

\subsection{Purification of Xylanase}

Purification of xylanase was performed in three steps. The first step was ammonium sulphate precipitation until $60-80 \%$ saturation was acquired. Purification with a fast-performance liquid chromatography (FPLC) system (Amersham Pharmacia Biotech, Piscataway, NJ) equipped with a HiTrap column (DEAE Sepharose) was the second step. Here, elution was carried out with a linear gradient of $0-1.0 \mathrm{M}$ sodium chloride $(\mathrm{NaCl})$ in $50 \mathrm{mM}$ phosphate buffer $(\mathrm{pH}$ 6.5) at flow rate of 1 $\mathrm{mL} \cdot \mathrm{min}^{-1}$. The dialyzed fraction $(15 \mathrm{~mL})$ was further loaded onto a Sephacryl S-200 column as the third step of purification. The protein was eluted with $20 \mathrm{mM}$ phosphate buffer $(\mathrm{pH} 7.0)$ at a constant flow rate of 0.5 $\mathrm{mL} \cdot \mathrm{min}^{-1}$. Fractions were collected and checked for the xylanase activity and protein concentration applying spectrophotometer at a wavelength of $280 \mathrm{~nm}\left(\mathrm{~A}_{280}\right)$. SDS-PAGE was performed according to the method described by Laemmli (19). Zymogram analysis was performed as per Muhammad, et al. (7) and samples were electrophoresed on $12 \%$ polyacrylamide gel containing $0.2 \%$ oat spelt xylan under denaturing conditions.

\subsection{Characterization of Xylanase}

3.4.1. Effect of $p H$ and Temperature on Xylanase Activity

The enzymatic reactions were carried out for $10 \mathrm{~min}$ at $50{ }^{\circ} \mathrm{C}$ in $50 \mathrm{mM}$ buffers with different $\mathrm{pH}$ ranging between 3.5 to 6 (sodium acetate), 6 to 8 (sodium phosphate) and 8 to 10.0 (sodium carbonate) for the estimation of relative activity. The maximum activity obtained was considered as $100 \%$ and used as a reference in determining relative activities at different $\mathrm{pH}$ values. The optimum temperature for activity of xylanase was determined by performing the standard reaction for $10 \mathrm{~min}$ at a temperature range of $20-90{ }^{\circ} \mathrm{C}$.

3.4.2. Determination of $p H$ Stability and Thermostability The stability as a function of $\mathrm{pH}$ was determined by calculating the residual activity at each $\mathrm{pH}$ mentioned 
above after $1 \mathrm{~h}$ of incubation at room temperature. Thermostability of the purified xylanase was determined by incubating the enzyme at different temperatures (20$90{ }^{\circ} \mathrm{C}$ ) for $30 \mathrm{~min}$. The residual activity was estimated under optimal conditions and the relative activity was calculated by taking activity before incubation as $100 \%$.

\subsubsection{Substrate Specificity}

The substrate specificity of the purified xylanase was determined using various substrates (1 \%): birchwood xylan, beechwood xylan, oat spelt xylan, wheat bran, rice bran, corn cob, sugarcane baggasse, carboxymethyl cellulose (CMC) and $p$-nitrophenyl- $\beta$ D-xylanopyranoside (pNPX). Levels of the produced reducing sugars were measured by DNS method as stated previously.

\subsubsection{Effect of Metal Ions and Protein Modifiers on Xylanase Activity}

The influence of numerous metal ions $\left(\mathrm{Hg}^{2+}, \mathrm{Ni}^{2+}, \mathrm{Zn}^{2+}\right.$, $\mathrm{Mg}^{2+}, \mathrm{Co}^{2+}, \mathrm{Na}^{+}, \mathrm{Fe}^{2+}, \mathrm{Mn}^{2+}, \mathrm{Ca}^{2+}, \mathrm{K}^{+}, \mathrm{Pb}^{2+} \& \mathrm{Ni}^{2+}$ ) on the purified xylanase activity was evaluated by including the appropriate metal ion salt in the standard assay solution (2 $\mathrm{mM}$ final concentration). To study the influence of the various amino acid modifying reagents such as, phenyl methane sulphonyl fluoride (PMSF), dimethyl sulfoxide (DMSO), ethylene diamine tetraacetic acid (EDTA), sodium dodecyl sulfate (SDS), dithiothreitol (DTT), $\beta$-mercaptoethanol, and isopropanol on xylanase activity were studied by incubating aliquots of the enzyme with different reagents $(5 \mathrm{mM}$ final concentration except isopropanol and DMSO at 1\%). The residual activity was determined using the standard assay procedure. The degree of inhibition or activation of the enzyme was expressed as a percentage of the enzyme activity in the control sample (no modifier was present) and the relative activity was calculated by considering enzyme activity in the control sample as $100 \%$.

\subsubsection{Enzymatic Hydrolysis of Xylan and Kinetic Parameters of $X y l B$}

The enzymatic hydrolysis of the various pure xylans and wheat bran was performed according to the appropriate method (20). The separated products of the hydrolysis were analyzed by the high performance liquid chromatography (HPLC, Shimadzu) using Phenomenex $\mathrm{NH}_{2}$ column and Refractive Index (RI) detector with acetonitrile (75\%) as mobile phase. The kinetic constants $K_{\mathrm{m}}$ and $V_{\max }$ were estimated following Lineweaver and Burk method (21) using beechwood xylan as substrate.
3.4.6. XOS Syrup Preparation Using Ultra Filtration (UF)

Enzymatic hydrolysate of the wheat bran was applied first to the UF system with a $10 \mathrm{kDa}$ MWCO membrane to separate high molecular weight polysaccharides. The oligosaccharide-containing permeate obtained here was processed by a second UF $3 \mathrm{kDa}$ MWCO membrane. Retentate and permeate, after each step, were analyzed for the total reducing sugars using DNS method. For qualitative and quantitative estimation of XOS, HPLC analysis was performed as mentioned above. The concentrations of oligosaccharides, separated by $\mathrm{NH}_{2}$ column, were quantified by comparing the average peak area of each sample with a mixture of standard oligosaccharides $\left(\mathrm{X}_{1}-\mathrm{X}_{5}\right)$ and expressed as milligrams per millilitres of the oligosaccharide.

3.4.7. In vitro Analysis of XOS Syrup (Prebiotic) - Effect on Growth Performance of the Selected Probiotics

The tested probiotic strains were Bacillus clausii (Sanofi Winthrop, Switzerland), Lactobacillus collinoides (IMTECH, Chandigarh), L. acidophilus KCET (Department of Biotechnology, Kamaraj College of Engineering \& Technology, Virudunagar, TN, India), L. lactis, L. acidophilus MKU, L. casei and L. brevis (Department of Biochemistry, Madurai Kamaraj University, Madurai, TN, India). A $0.5 \mathrm{~mL}$ (0.5\% sugar conc.) of XOS syrup was added to M9 minimal media and incubated with the respective overnight cultures. The Media inoculated with the culture in absence of XOS syrup was taken as control. Aliquot of each culture was taken after every 2-6 $\mathrm{h}$ and the optical density at $600 \mathrm{~nm}$ and $650 \mathrm{~nm}$ was determined for up to $72 \mathrm{~h}$, respectively. The experiment was carried out in triplicates and the mean values were plotted. Subsequently, specific growth rates of the probiotics in the presence and absence of XOS syrup was calculated as per following equation:

$$
\text { Specific growth rate }(\mu)=K^{\prime}=\frac{\ln \left(\frac{m t^{2}}{m t^{1}}\right)}{t^{2}-t^{1}}
$$

where, $t^{1}$ and $t^{2}$ the initial and final times, $m$ is the concentration of cells and $K$ is the growth rate constant.

\subsubsection{Statistical Analysis}

The experimental data was expressed as mean values. One way Analysis of Variance (ANOVA) was carried out using SIGMASTAT 3.5 to determine the difference between crude and purified protein samples. 
Table 1. Summary of purification of xylanases produced by B. pumilus B20 under submerged fermentation $(\mathrm{SmF})$ condition.

\begin{tabular}{|c|c|c|c|c|c|c|}
\hline Column & $\begin{array}{l}\text { Volume } \\
\text { (mL) }\end{array}$ & $\begin{array}{c}\text { aTotal endoxylanase } \\
\text { activity } \\
(\mathrm{U} \times \mathbf{1 0 0 0})\end{array}$ & $\begin{array}{l}{ }^{\text {b}} \text { Total } \\
\text { protein } \\
(\mathbf{m g})\end{array}$ & $\begin{array}{l}\text { Specific } \\
\text { activity } \\
\left(\mathrm{U} \cdot \mathrm{mg}^{-1}\right)\end{array}$ & $\begin{array}{l}\text { Recovery } \\
\qquad(\%)\end{array}$ & $\begin{array}{l}\text { Purification } \\
\quad \text { (fold) }\end{array}$ \\
\hline Crude & 1000 & $306.6 \pm 2.15$ & $6000.0 \pm 12$ & 51.1 & 100 & 1 \\
\hline $\begin{array}{l}60-80 \% \\
\text { Ammonium Sulphate }\end{array}$ & 52 & $227.5 \pm 1.31$ & $876.60 \pm 4.15$ & 258.40 & 73.88 & 5.05 \\
\hline $\begin{array}{l}\text { Ion exchange } \\
\text { chromatography }\end{array}$ & 15 & $124.1 \pm 2.65$ & $411.64 \pm 0.96$ & 301.52 & 41 & 5.9 \\
\hline $\begin{array}{l}\text { Gel filtration } \\
\text { chromatography }\end{array}$ & 10 & $90.3 \pm 2.15$ & $119.50 \pm 1.16$ & 755.81 & 29.45 & 14.8 \\
\hline
\end{tabular}

${ }^{a, b}$ Mean \pm standard deviation of two the replicate determinations. Different letters indicate significant differences according to one way ANOVA $(p<0.05)$

\section{Results}

\subsection{Purification of Xylanase, XylB, from B. pumilus B20}

Table 1 depicts the stages of purification. The dialyzed fraction, after ammonium sulphate precipitation, contained 4375 U.mL ${ }^{-1}$ of xylanase activity with a purification factor of 5.05. The xylanase from this fraction was further purified through DEAE-Sepharose column chromatography and eluted with a linear gradient of 0.1 to $1 \mathrm{M}$ of $\mathrm{NaCl}$. Fractions exhibiting xylanase activity were pooled and subjected to the gel filtration chromatography using Sephacryl S-200 column (Fig. 1). A major protein peak exhibiting maximum xylanase activity was obtained. Based on the enzyme activity $\left(90,300 \mathrm{U} .10 \mathrm{~mL}^{-1}\right)$ and the total protein content $\left(119.50 \mathrm{mg} .10 \mathrm{~mL}^{-1}\right)$ of the collected sample, the specific activity of the purified xylanase (XylB) was found to be $755.81 \mathrm{U}_{\mathrm{mg}}{ }^{-1}$. Samples from all stages of xylanase purification have shown a

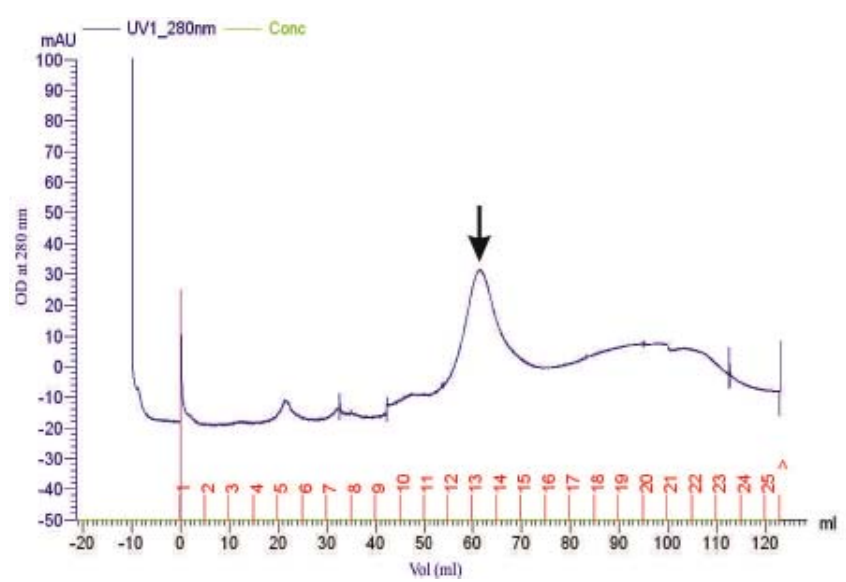

Figure 1. Gel filtration purification profile of the partially purified xylanase on sephacryl S-200. Arrow shows the fraction with the highest activity. significant xylanase activity and protein concentration $(p \leq 0.05)$. The recovery of xylanase was $29.45 \%$, with a purification factor of 14.8 . The purified xylanase preparation was used in subsequent experiments.

\subsection{Characterization of $X y l B$ \\ 4.2.1. Molecular Weight Determination}

The molecular weight of XylB was approximately 85 $\mathrm{kDa}$ (Fig. 2A). The appearance of a zone of clearance in the zymogram confirmed the xylanolytic activity of the purified protein XylB (Fig. 2B).

\subsubsection{Effect of $p H$ and Temperature on XylB Activity and Stability}

On the one hand, XylB showed the maximum activity at $\mathrm{pH} 6.5$ (Fig. 3A). At pH 6.0 and 7.0, the enzyme displayed $98 \%$ of the maximum activity. A steep decline in the activity at alkaline $\mathrm{pH} 9.0$ was observed, while at $\mathrm{pH} 10$ there was a complete loss of activity. On the other hand, XylB exhibited the maximum stability in the range of $\mathrm{pH} 6.5$ to 7.5 when pre-incubated for 1 $\mathrm{h}$ at room temperature in buffers with different $\mathrm{pH}(\mathrm{pH}$ 3.5-10.0) (Fig. 3A).

The activity profile of $\mathrm{XylB}$ at various temperatures $\left(20\right.$ to $90{ }^{\circ} \mathrm{C}$ ) has demonstrated a maximum activity at $60{ }^{\circ} \mathrm{C}$ (Fig. 3B). At 40 and $50^{\circ} \mathrm{C}$, XylB has displayed 58 $\%$ and $64.6 \%$ of the maximum activity, respectively. At $80{ }^{\circ} \mathrm{C}$, there was $50 \%$ decline in the activity (44.24\%). When pre-incubated for $30 \mathrm{~min}$ at various temperatures (20- $90{ }^{\circ} \mathrm{C}$ ), $\mathrm{XylB}$ showed stability from $20^{\circ} \mathrm{C}$ to $50^{\circ} \mathrm{C}$, after which there was a decline in the activity (Fig. 3B).

\subsubsection{Substrate Specificity for XylB}

The hydrolysis of various substrates by purified XylB was examined and the results are presented in Table 2. Statistical analysis revealed a significant difference in 


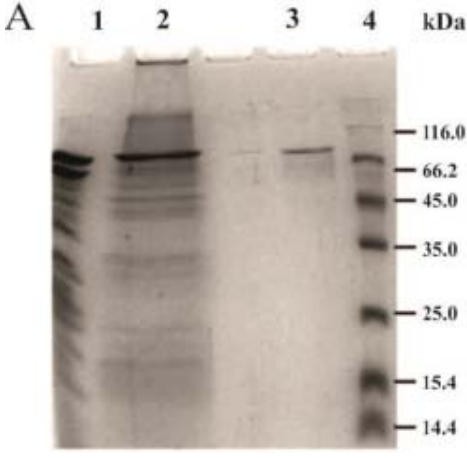

Figure 2. A. SDS-PAGE analysis of the purified xylanase (XylB) from B. pumilus B20. Lane 1-Ammonium sulphate fractionated $\&$ dialysed protein. Lane 2-Partially purified xylanase protein sample from Ion exchange chromatography. Lane 3-Purified $\sim 85 \mathrm{kDa}$ endoxylanase (XylB). Lane 4-Molecular weight standards 14.4-116 kDa. B. Zymogram analysis of the purified xylanase.
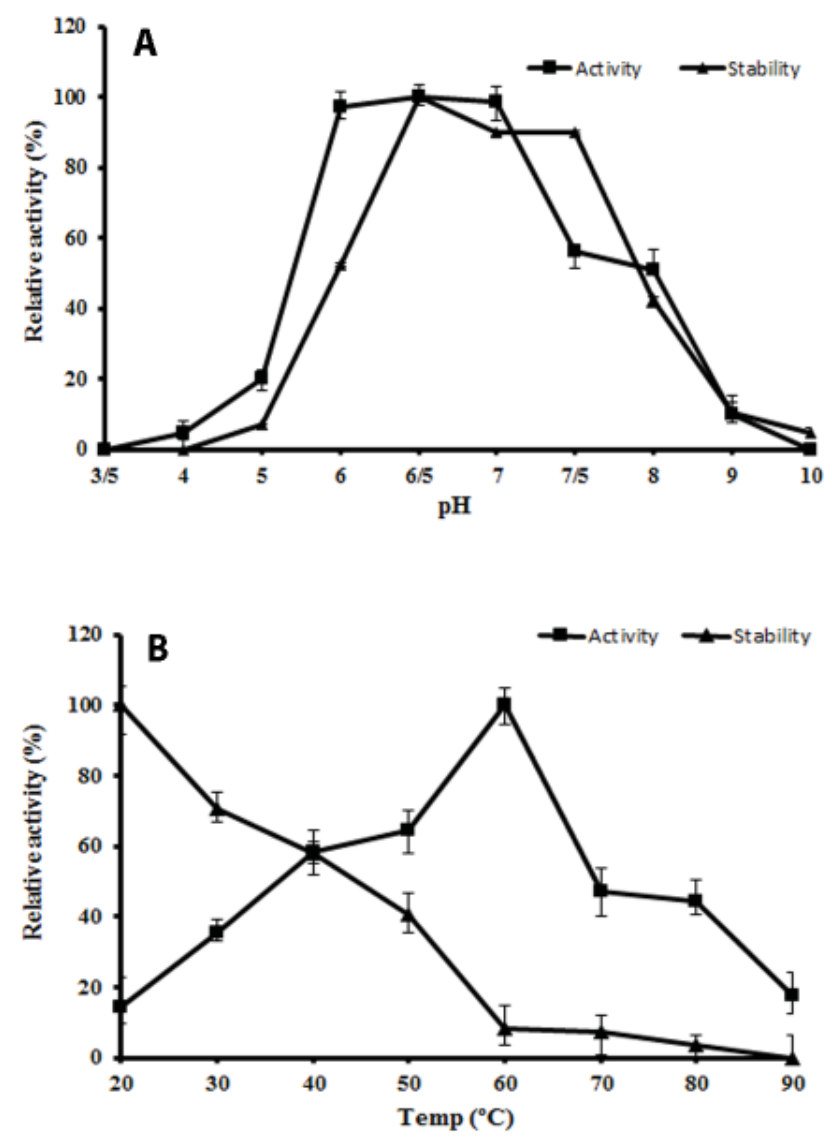

Figure 3. Effect of $\mathrm{pH}$ and temperature on XylB activity and stability. A: Effect of $\mathrm{pH}$ on the activity (----) and stability $\left(--\mathbf{A}^{--}\right)$of XylB. B: Effect of temperature on the activity (---) and stability (-- $\mathbf{\Lambda}--)$ of XylB.
Table 2. Relative specificity of XylB towards different substrates.

\begin{tabular}{llc}
\hline S.No. & Substrate & a Relative activity $(\%)$ \\
\hline 1 & Oat spelt xylan & $18.57 \pm 0.02$ \\
2 & Beechwood xylan & $52.14 \pm 0.15$ \\
3 & Birchwood xylan & $18.57 \pm 0.2$ \\
4 & Wheat bran & $100.00 \pm 0.15$ \\
5 & Corn cob & $90.00 \pm 0.09$ \\
6 & Rice straw & $0.00 \pm 0.13$ \\
7 & Sugarcane baggasse & $35.71 \pm 0.1$ \\
8 & Carboxymethyl cellulose & $0.00 \pm 0.12$ \\
9 & pNPX & $0.00 \pm 1.1$ \\
\hline
\end{tabular}

${ }^{\mathrm{a}}$ Mean \pm standard deviation of the three replicate determinations. The statistical analysis was done using one way ANOVA with $p$ value $<0.05$.

the specificity of XylB for various substrates $(p \leq 0.05)$. XylB showed a maximum hydrolysis of wheat bran. The high specificity of XylB towards wheat bran will enable industries to produce XOS at low cost.

\subsubsection{Effect of Metal Ions and Protein Modifiers on Xylanase Activity}

The effect of probable inhibitors and activators on XylB is presented in Table $3 . \mathrm{Hg}^{+}$and $\mathrm{Cu}^{2+}$ ions strongly repressed the activity of XylB, while $\mathrm{Co}^{2+}, \mathrm{Na}^{+}$, and $\mathrm{Fe}^{2+}$ salts improved XylB activity. On the other hand, $\mathrm{Zn}^{2+}$, $\mathrm{Mn}^{2+}, \mathrm{Mg}^{2+}, \mathrm{Ca}^{2+}$ and $\mathrm{K}^{+}$did not have any influence on the activity of XylB. $\mathrm{Pb}^{2+}$ and $\mathrm{Ni}^{2+}$ had a negative effect on XylB activity, too. Further, the activity of XylB was not affected by PMSF and DMSO, whereas EDTA and SDS inhibited XylB activity significantly. On the other hand, the activity of XylB was increased by DTT, $\beta$-mercaptoethanol and isopropanol. The activation of xylanase following to treatment with $\beta$-mercaptoethanol proved the promising role of L-cysteine in the catalytic activity of XylB.

\subsubsection{Hydrolysis Profile of Xylans}

The hydrolysis of pure xylan and wheat bran by XylB was studied using HPLC analysis. The hydrolysis of oat spelt xylan (OSX) and wheat bran resulted in xylobiose $\left(\mathrm{X}_{2}\right)$ as major product followed by xylotriose $\left(\mathrm{X}_{3}\right)$. In contrast, hydrolysis of birch wood xylan (BWX) resulted in $\mathrm{X}_{4}$ as a major product while $\mathrm{X}_{2}, \mathrm{X}_{3}, \mathrm{X}_{5}$ and $\mathrm{X}_{6}$ were minor products. The hydrolysis of beech wood xylan (BEX) resulted in $\mathrm{X}_{2}$ and $\mathrm{X}_{4}$ as the major products with other higher oligosaccharides as minor products. There was a negligible concentration of xylose $\left(\mathrm{X}_{1}\right)$ indicating that XylB is probably an endoxylanase. The hydrolysate of wheat bran was used for XOS syrup preparation. 
Table 3. Effect of metal ions and inhibitors on the activity of XylB.

\begin{tabular}{lccccc}
\hline S. No. & Reagents (2 mM) & $\begin{array}{c}\text { Relative } \\
\text { Activity (\%) }\end{array}$ & $\begin{array}{c}\text { S. } \\
\text { No. }\end{array}$ & Reagents (2 mM) & $\begin{array}{c}\text { Relative } \\
\text { Activity (\%) }\end{array}$ \\
\hline 1 & $\mathrm{Control}_{2}$ & 100.00 & 11 & $\mathrm{CaCl}_{2} \cdot 2 \mathrm{H}_{2} \mathrm{O}$ & 80.12 \\
2 & $\mathrm{CoCl}_{2} \cdot 6 \mathrm{H}_{2} \mathrm{O}$ & 301.20 & 12 & $\mathrm{FeSO}_{4} \cdot 7 \mathrm{H}_{2} \mathrm{O}$ & 144.57 \\
3 & $\mathrm{HgCl}_{2}$ & 0.00 & 13 & $\mathrm{NiSO}_{4}$ & 43.97 \\
4 & $\mathrm{MgSO}_{4}$ & 72.28 & 14 & DTT (5mM) & 244.57 \\
5 & $\mathrm{CuSO}_{4} \cdot 5 \mathrm{H}_{2} \mathrm{O}$ & 0.00 & 15 & $2-\mathrm{Mercaptoethanol}(5 \mathrm{mM})$ & 170.48 \\
6 & $\mathrm{ZnSO}_{4} \cdot 7 \mathrm{H}_{2} \mathrm{O}$ & 92.16 & 16 & $\mathrm{SDS}(5 \mathrm{mM})$ & 12.00 \\
7 & $\mathrm{MnCl}_{2} \cdot 4 \mathrm{H}_{2} \mathrm{O}$ & 108.43 & 17 & EDTA (5mM) & 31.92 \\
8 & $\mathrm{NaCl}$ & 126.50 & 18 & PMSF (5mM) & 96.38 \\
9 & $\mathrm{KCl}$ & 102.40 & 19 & Isopropanol (1\%) & 126.50 \\
10 & $\mathrm{~Pb}\left(\mathrm{CH}_{3} \mathrm{COO}\right)_{2} \cdot 3 \mathrm{H}_{2} \mathrm{O}$ & 48.19 & 20 & DMSF (1\%) & 100.00 \\
\hline
\end{tabular}

Table 4. Recovery of oligosaccharide in the final permeate of 10 and $3 \mathrm{kDa}$ MWCO membrane.

\begin{tabular}{|c|c|c|c|}
\hline Oligosaccharide & $\begin{array}{l}\text { Initial feed amount } \\
\quad\left(\mathrm{mg}^{\mathrm{a}} \mathrm{ml}^{-1}\right)\end{array}$ & $\begin{array}{c}{ }^{\mathrm{b}} \mathrm{MWCO} 10 \mathrm{kDa} \\
\%\end{array}$ & $\begin{array}{c}\text { MWCO } 3 \text { kDa } \\
\%\end{array}$ \\
\hline Total & $1.8 \pm 0.6$ & 72.22 & 44.44 \\
\hline$>X_{5}$ & $1.05 \pm 0.2$ & 52.38 & 28.57 \\
\hline $\mathrm{X}_{5}$ & $0.04 \pm 0.4$ & 99.50 & 75.35 \\
\hline $\mathrm{X}_{4}$ & $0.08 \pm 0.2$ & 75.00 & 50.00 \\
\hline $\mathrm{X}_{3}$ & $0.1 \pm 0.2$ & 90.10 & 60.25 \\
\hline $\mathrm{X}_{2}$ & $0.51 \pm 0.2$ & 99.50 & 66.66 \\
\hline $\mathrm{X}_{1}$ & $0.007 \pm 0.2$ & 98.00 & 98.30 \\
\hline
\end{tabular}

${ }^{a}$ Mean \pm standard deviation of two replicate determinations.

${ }^{\mathrm{b}}$ MWCO stands for Molecular Weight Cutoff Membrane

\subsubsection{Kinetic Parameters Determination}

The kinetic parameters of XylB were determined at $60^{\circ} \mathrm{C}$ and $\mathrm{pH} 6.5$ by using oat spelt xylan as substrate. The $K_{\max }$ and $V_{\max }$ values of the purified XylB were 2.3 $\mathrm{mg} \cdot \mathrm{mL}^{-1}$ and $50 \mu \mathrm{M} \mathrm{min}{ }^{-1} \cdot \mathrm{mg}^{-1}$ respectively.

\subsection{XOS Syrup (Prebiotics) Preparation Using Ultra Filtration}

The HPLC analysis of the permeate from $10 \mathrm{kDa}$ MWCO membrane confirmed the presence of XOS ranging from $X_{1}$ to longer than $X_{5}$, whereas the retentate has contained the high molecular weight polysaccharides. After a second ultrafiltration step with $3 \mathrm{kDa}$ MWCO membrane, the final permeate showed high concentrations of XOS with degree of polymerization (DP) 2-5 and small concentrations of higher molecular weight XOS $\left(>X_{5}\right)$ and xylose. The percentage recoveries of $X_{1}, X_{2}, X_{3}, X_{4}$, and $>X_{5}$ in permeate is given in Table 4 .
4.4. Effect of XOS Syrup (Prebiotic) on Growth Performance of the Selected Probiotics - An In vitro Study

The influence of varying concentrations of XOS syrup, in the minimal medium, on probiotic organism's growth is shown in Figure 4. The percentage of the total sugar concentration was found to be directly proportional to the increase in the growth rate of the probiotic strains. Hence, XOS syrup with $0.5 \%$ sugar concentration was selected for further study.

The highest growth rate of probiotic strains was found in media with XOS syrup as the sole carbon and energy source (Fig. 5). Among all the probiotic strains tested, Lactobacillus brevis showed maximum growth in the presence of $0.5 \%$ XOS syrup with a specific growth rate of $1.2 \mathrm{~h}^{-1}$. For Bacillus clausii, the maximum growth was observed at the $8^{\text {th }}$ hour with a specific growth rate of $0.6 \mathrm{~h}^{-1}$. Thus, XOS syrup was utilized effectively to enhance the growth of probiotic strains in the absence of other carbon sources. 


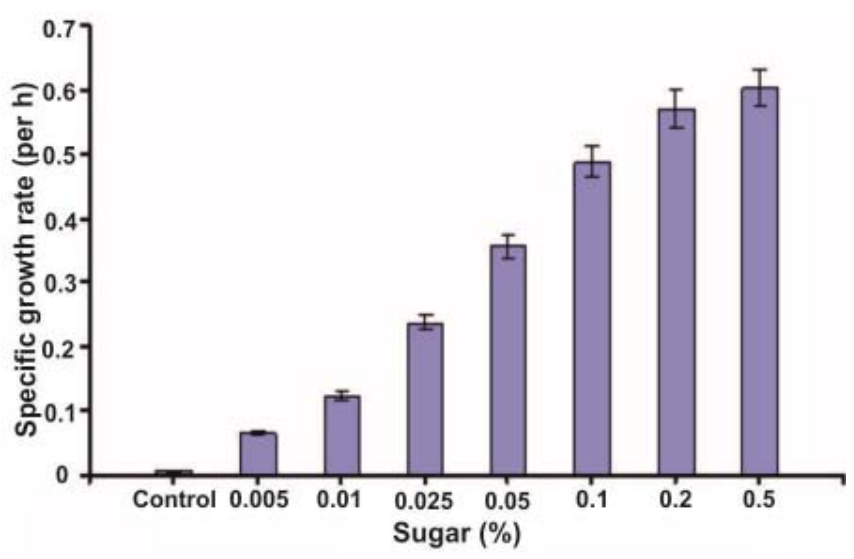

Figure 4. Effect of different concentrations of XOS syrup on growth of probiotic strain an in vitro study.

\section{Discussion}

The endoxylanase, XylB, purified from B. pumilus B20, exhibited the general properties analogous to xylanases reported in literature (22). The specific activity of the purified xylanase has been reported to be in the range of $5.33 \mathrm{IU} \mathrm{mg}^{-1}$ in $B$. acidocaldarius (23) to $3,626 \mathrm{IU} \mathrm{mg}^{-1}$ in Clostridium stercorarium (24). The specific activity of XylB (755.81 U.mg-1) is obviously in the medium range indicating that it may be the ideal enzyme for use in the industrial processes.

As per literature, the optimum $\mathrm{pH}$ of the purified xylanase from B. pumilus (8) and B. subtilis (25) was 6.5 and 6.0 respectively, which correlates with our data. Temperature studies on xylanase revealed maximum XylB activity at $60{ }^{\circ} \mathrm{C}$ corresponding with a number of reports indicating the optimal temperature ranging between 40 and $70{ }^{\circ} \mathrm{C}$ (26). Similarly, xylanase from Bacillus coagulans BL69, grown on soya-bean residues (27), showed activity over a wide range of temperatures $\left(45-75^{\circ} \mathrm{C}\right)$. Hence, XylB can also be considered as an ideal candidate for the enzymatic hydrolysis of paper and pulp to improve the economics of the process of paper production. XylB had very weak CMCase and $\beta$-xylosidase activities proving that it can specifically cleave the xylosyl $\beta-1,4$ linkages resulting in formation of high value XOS. Similar substrate specificity was observed in xylanase from Fusarium oxysporum and $T$. lanuginosus $(28,29,30,31)$. But some xylanases have been reported to possess cellulase activity also (32). These characteristics of xylanase from B. pumilus B20 will be useful in the production of prebiotics which are functional food.

Purification of XOS with DP 2-10 has been carried out by membrane techniques in order to eliminate both XOS (within the undesired DP range) and non-

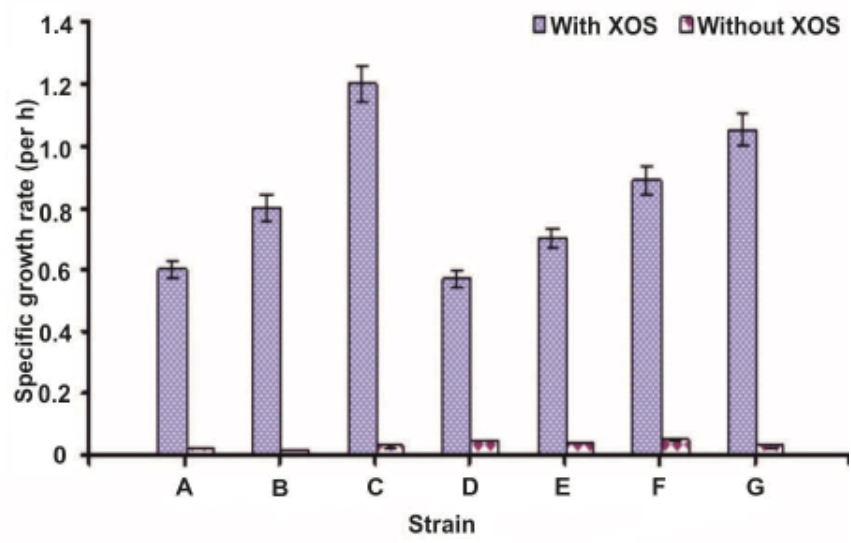

Figure 5. Growth rates $\left(\mathrm{h}^{-1}\right)$ of probiotic strains utilizing XOS syrup as carbon source. A, Bacillus clausii; B, Lactobacillus collinoides; C, L. brevis; D, L. lactis; E, L. acidophilus MKU; F, L. casei and G, L. acidophilus KCET.

saccharide compounds (33). Swennen et al. (34), in his study, used ultrafiltration with 5, 10, and $30 \mathrm{kDa}$ MWCO membranes for the segregation of enzymatically produced arabino-xylo-oligosaccharides from wheat xylan that were more heterogeneous and poly-dispersed than the fractions obtained with 1 and $3 \mathrm{kDa}$ MWCO membranes. Our study established that wheat bran, which has little economic value, could be converted to a more valuable XOS product, by enzymatic hydrolysis, without significant quantities of xylose.

Probiotic strains like Bifidobacteria, Bacilli and Lactobacilli improve resistance against gut infections by inhibiting growth of harmful bacteria, reducing cholesterol levels, immune response enhancement, and an increased production of vitamins (35). The probiotic nature of $B$. clausii has been attributed to its excellent tolerability with minimum side-effects (36). Studies on prebiotics have shown that when used as the sole carbon source, there is a considerable increase in Bifidobacterium numbers during a short-term intervention (35).

\section{Conclusion}

The endoxylanase, XylB, has been purified to homogeneity using a three-step purification protocol. XylB was used for production of industrially useful prebiotic XOS syrup using agricultural lignocellulosic waste, wheat bran, as substrate. This study provides a cost-effective method for enhancing the growth of probiotics with the help of XOS syrup. Although human gut probiotics can be used as a good model system for in vitro study in the early development of potential prebiotic oligosaccharides, confirmation of prebiotic activity can only be derived from in vivo feeding studies using animal models. 


\section{Acknowledgements}

The authors thank the Department of Biotechnology (DBT), New Delhi, for the financial support through the project (no.BT/PR-7451/PID/20/284/2006) and University Grants Commission (UGC), India, for providing meritorious student research fellowship in Biosciences (No. F. 4-1/2006 (BSR)/5-67/2007). Authors also thank management, principal, and Department of Biotechnology, Kamaraj College of Engineering and Technology, Virudhunagar, Tamil Nadu, India for their constant support and encouragement. A special thanks to Dr. Beatrice Anne D'Couto, Associate Professor, Department of English, Lady Doak College, Madurai, Tamil Nadu, India, for her time and help in extensive English editing of the manuscript.

\section{References}

1. Puls J. Chemistry and biochemistry of hemicelluloses: Relationship between hemicellulose structure and enzymes required for hydrolysis. Macromol Symposia. 1997;120(1):183196. DOI: 10.1002/masy.19971200119.

2. Collins T, Gerday C, Feller G. Xylanases, xylanase families and extremophilic xylanases. FEMS Microbiol Lett. 2005;29(1):323. DOI: 10.1016/j.femsre.2004.06.005.

3. Coughlan MP, Hazlewood GP. beta-1,4-D-xylan-degrading enzyme systems: biochemistry, molecular biology and applications. Biotechnol Appl Biochem. 1993;17(3):259-289. DOI: 10.1111/j.1470-8744.1993.tb00244.x.

4. Fialho MB, Carmona EC. Purification and characterization of xylanases from Aspergillus giganteus. Folia Microbiologica 2004;49(1):13-18. DOI: 10.1007/bf02931639.

5. Frederick MM, Kiang C-H, Frederick JR, Reilly PJ. Purification and characterization of endo-xylanases from Aspergillus niger. I. Two isozymes active on xylan backbones near branch points. Biotechnol Bioeng. 1985;27(4):525-532. DOI: 10.1002/ bit.260270420.

6. Gandhi JP, Rao KK, Dave PJ. Characterization of extracellular thermostable xylanase from Chaetomium globosum. J Chem Technol Biotechnol. 1994;60(1):55-60. DOI: 10.1002/ jctb.280600109.

7. Muhammad I, Muhammad N,Quratualain S. Purification and kinetics study of thermostable cellulase free Xylanase from Bacillus subtilis. Protein Pept Lett. 2013;20(11):1225-1231. DOI: $10.2174 / 09298665113209990007$.

8. Panbangred W, Shinmyo A, Kinoshita S,Okada H. Purification and Properties of Endoxylanase Produced by Bacillus pumilus. Agric Biol Chem. 1983;47(5):957-963. DOI: 10.1080/00021369.1983.10865760.

9. Lumba FL,Penninckx MJ. Characterization of the multiple forms of $\beta$-xylanase produced by a Streptomyces sp. growing on lignocellulose. Appl Microbiol Biotechnol. 1992;36(6):733738. DOI: $10.1007 /$ bf00172184.

10. Soltanali S,Ziaie-Shirkolaee Y. Biobleaching of Bagasse Pulp with Xylanase Enzymes and Hydrogen Peroxide. Iran J Biotech. 2007;5(3):170-177.

11. Romanowska I, Polak J,Bielecki S. Isolation and properties of Aspergillus niger IBT-90 xylanase for bakery. Appl Microbiol
Biotechnol. 2006;69(6):665-671. DOI: 10.1007/s00253-0050011-0.

12. Kung Jr. L, Treacher RJ, Nauman GA, Smagala AM, Endres KM,Cohen MA. The Effect of Treating Forages with Fibrolytic Enzymes on its Nutritive Value and Lactation Performance of Dairy Cows. J Dairy Sci. 2000;83(1):115-122. DOI: 10.3168/ jds.S0022-0302(00)74862-4.

13. George SP, Ahmad A, Rao MB. A novel thermostable xylanase from Thermomonospora sp.: influence of additives on thermostability. Bioresour Technol.2001;78(3):221-224. DOI: 10.1016/S0960-8524(01)00029-3.

14. Geetha K, Gunasekaran P. Optimization of nutrient medium containing agricultural waste for xylanase production by Bacillus pumilus B20. Biotechnol Bioprocess Eng. 2010;15(5):882-889. 10.1007/s12257-009-3094-0.

15. Bailey MJ, Biely P, Poutanen K. Interlaboratory testing of methods for assay of xylanase activity. $J$ Biotechnol. 1992;23(3):257-270. DOI: 10.1016/0168-1656(92)90074-J.

16. Miller GL. Use of Dinitrosalicylic Acid Reagent for Determination of Reducing Sugar. Anal Chem. 1959;31(3):426428. DOI: $10.1021 / \mathrm{ac} 60147 \mathrm{a} 030$.

17. Lynd LR, Weimer PJ, van Zyl WH, Pretorius IS. Microbial Cellulose Utilization: Fundamentals and Biotechnology. Microbiol Mol Biol Rev. 2002;66(3):506-577. DOI: 10.1128/ MMBR.66.3.506-577.2002.

18. Lowry OH, Rosebrough NJ, Farr AL, Randall RJ. Protein measurements with folin-phenol reagent. $J$ Biol Chem. 1951;193(1):265-275.

19. Laemmli UK. Cleavage of Structural Proteins during the Assembly of the Head of Bacteriophage T4. Nature (London) 1970;227(5259):680-685. DOI: 10.1038/227680a0.

20. Matte A, Forsberg CW. Purification, characterization, and mode of action of endoxylanases 1 and 2 from Fibrobacter succinogenes S85. Appl Environ Microbiol. 1992;58(1):157168.

21. Lineweaver H,Burk D. The Determination of Enzyme Dissociation Constants. J Am Chem Soc. 1934;56(3):658-666. DOI: $10.1021 / \mathrm{ja} 01318 \mathrm{a} 036$.

22. Henrissat B, Bairoch A. Updating the sequencebased classification of glycosyl hydrolases. Biochem $J$. 1996;316(2):695-696. DOI: 10.1042/bj3160695.

23. UchinoF, NakaneT.AThermostableXylanasefromaThermophilic Acidophilic Bacillus sp. Agric Biol Chem. 1981;45(5):11211127. DOI: $10.1080 / 00021369.1981 .10864666$.

24. Bérenger J-F, Frixon C, Bigliardi J, Creuzet N. Production, purification, and properties of thermostable xylanase from Clostridium stercorarium. Can J Microbiol. 1985;31(7):635643. DOI: $10.1139 / \mathrm{m} 85-120$.

25. Sá-Pereira P, Costa-Ferreira M,Aires-Barros MR. Enzymatic properties of a neutral endo-1,3(4)- $\beta$-xylanase Xyl II from Bacillus subtilis. J Biotechnol. 2002;94(3):265-275. DOI: 10.1016/S0168-1656(01)00436-9.

26. Garfin DE. Isoelectric focusing. In: Murray PD, editors. Methods in Enzymology. Academic Press. 1990;182:459-477. DOI: 10.1016/0076-6879(90)82037-3.

27. Heck JX, Flôres SH, Hertz PF,Ayub MAZ. Optimization of cellulase-free xylanase activity produced by Bacillus coagulans BL69 in solid-state cultivation. Pro Biochem. 2005;40(1):107112. DOI: 10.1016/j.procbio.2003.11.044.

28. Christakopoulos P, Nerinckx W, Kekos D, Macris B,Claeyssens M. Purification and characterization of two low molecular mass 


\section{Geetha K \& Gunasekaran P}

alkaline xylanases from Fusarium oxysporum F3. J Biotechnol. 1996;51(2):181-189. DOI: 10.1016/0168-1656(96)01619-7.

29. Lin J, Ndlovu LM, Singh S,Pillay B. Purification and biochemical characteristics of $\beta$-D-xylanase from a thermophilic fungus, Thermomyces lanuginosus-SSBP. Biotechnol Appl Biochem. 1999;30(1):73-79. DOI: 10.1111/j.1470-8744.1999.tb01162.x.

30. He J, Su L, Sun X, Fu J, Chen J,Wu J. A novel xylanase from Streptomyces sp. FA1: Purification, characterization, identification, and heterologous expression. Biotechnol Bioprocess Eng. 2014;19(1):8-17. DOI: 10.1007/s12257-0130490-2.

31. Kamble RD, Jadhav AR. Isolation, Purification, and Characterization of Xylanase Produced by a New Species of Bacillus in Solid State Fermentation. Int $J$ Microbiol. 2011;2012:1-8. DOI: 10.1155/2012/683193.

32. Kang MK, Maeng PJ, RheeYH. Purification and Characterization of Two Xylanases from Alkalophilic Cephalosporium sp. Strain RYM-202. Appl Environ Microbiol. 1996;62(9):3480-3482.
33. Crittenden RG, Playne MJ. Production, properties and applications of food-grade oligosaccharides. Trends Food Sci Technol. 1996;7(11):353-361. DOI: 10.1016/S09242244(96)10038-8.

34. Swennen K, Courtin CM, Van der Bruggen B, Vandecasteele C,Delcour JA. Ultrafiltration and ethanol precipitation for isolation of arabinoxylooligosaccharides with different structures. Carbohydr Polym. 2005;62(3):283-292. DOI: 10.1016/j.carbpol.2005.08.001.

35. Costabile A, Deaville ER, Morales AM,Gibson GR. Prebiotic Potential of a Maize-Based Soluble Fibre and Impact of Dose on the Human Gut Microbiota. PLoS One. 2016;11(1):e0144457. DOI: 10.1371/journal.pone.0144457.

36. Bozdogan B, Galopin S, Gerbaud G, Courvalin P, Leclercq R. Chromosomal aadD2 Encodes an Aminoglycoside Nucleotidyltransferase in Bacillus clausii. Antimicrob Agents Chemother. 2003;47(4):1343-1346. DOI: 10.1128/ aac.47.4.1343-1346.2003. 